\title{
ANATOMIA FOLIAR DE Mentha $x$ villosa HUDS SOB DIFERENTES ESPECTROS DE LUZ
}

\author{
Cláudia de Oliveira Gonçalves Nogueira \\ Docente do curso de Ciências Biológicas do UNIFOR-MG \\ e-mail: cogn@uai.com.br \\ Elias Alves da Silva \\ Discente do curso de Ciências Biológicas \\ Bolsista do Programa de Iniciação Científica do UNIFOR-MG \\ e-mail: eliasbiologo@ hotmail.com \\ Rennê Fonseca Ferreira \\ Melina Flávia Siqueira \\ Graduandos do curso de Agronomia da UFLA-MG \\ e-mail: rennefonseca@yahoo.com.br \\ melina-siqueira@hotmail.com \\ Adriana Tiemi Nakamura \\ Docente do Departamento de Biologia-UFLA-MG \\ e-mail: nakamura@dbi.ufla.br
}

\begin{abstract}
RESUMO
A hortelã, uma planta medicinal, teve amostras cultivadas em diferentes espectros de luminosidade: sob pleno sol (controle) e sob malhas coloridas, vermelha e preta, objetivando a comparação da anatomia do mesofilo foliar. Folhas das plantas conduzidas nos três tratamentos foram fixadas e conservadas em etanol a 70 \%. Lâminas semi-permanentes foram confeccionadas a partir de técnicas usuais em anatomia vegetal. Verificou-se que a anatomia foliar é, no geral, semelhante entre os três tratamentos, embora algumas modificações sejam constatadas, como: variação na sinuosidade das células epidérmicas comuns na planta sob pleno sol; ausência de tricomas tectores nas plantas cultivadas sob malha vermelha; presença de duas camadas de parênquima paliçádico na planta sob malha preta; variação no tamanho do sistema vascular entre os três tratamentos. Esses dados ressaltam que a diferença na qualidade da luz que chega à planta altera a anatomia foliar e possivelmente pode alterar a produção de compostos fármacos da planta, quando cultivada sob diferentes malhas coloridas.
\end{abstract}

Palavras-chave: Luminosidade. Modulação spectral. Tricomas.

\section{LEAF ANATOMY OF Mentha $x$ villosa HUDS UNDER DIFFERENT LIGHT SPECTRA}

\begin{abstract}
The mint, a medicinal plant, samples had grown in different spectra of light: full sunlight
\end{abstract}


(control) and under colored nets, red and black, in order to compare the anatomy of the leaf mesophyll. Leaves of plants cultivated in the three treatments were fixed and preserved in $70 \%$ ethanol. Semi-permanent slides were made from the usual techniques of plant anatomy. It was found that the leaf anatomy is generally similar among the three treatments, although some modifications are found, such as variation in sinuosity of the ordinary epidermal cells in the plant under full sun, absence of trichomes in plants grown under red shading; presence of two layers of palisade parenchyma in the plant under a black mesh; variation in the size of the vascular system between the three treatments. These data underscore the difference in the quality of light reaching the plant changes the leaf anatomy and can potentially alter the production of drug compounds from the plant when grown under different colored nets.

Keywords: Brightness. Modulation spectra. Trichomes.

\section{INTRODUÇÃO}

A hortelã, Mentha x villosa Huds, é uma espécie pertencente à Lamiaceae, família que abrange cerca de 200 gêneros e 3.200 espécies, de distribuição cosmopolita. A utilização de plantas medicinais tem sido estimulada, em parte, pela crescente demanda da indústria por novas fontes naturais de medicamentos e, por outro, devido aos efeitos colaterais causados pelos farmacossintéticos. (BERG, 1993).

Para um melhor aproveitamento do potencial fármaco da hortelã, faz-se necessário o estudo dessa espécie em diferentes ambientes, a fim de determinar o efeito da variação da luminosidade sobre a estrutura foliar do indivíduo, verificando a melhor faixa espectral para o cultivo dessa espécie.

A anatomia foliar pode ser grandemente influenciada pela radiação recebida durante o crescimento, uma vez que a folha é um órgão plástico e sua estrutura interna adapta-se às condições externas do ambiente. (HANDA et al, 2002; SCHLUTER et al, 2007).

No presente estudo, objetivou-se comparar a anatomia do mesofilo foliar de plantas sob o efeito da variação de luminosidade, utilizando malhas coloridas, preta e vermelha e sob pleno sol. Dessa forma, este estudo poderá auxiliar na escolha da melhor faixa espectral para o cultivo em larga escala desta espécie.

\section{METODOLOGIA}

Plantas de hortelã da espécie Mentha x villosa Huds foram cultivadas no viveiro de 
plantas do clube do UNIFOR. Foram realizados três tratamentos (cultivos): pleno sol e sob malhas coloridas: preta e vermelha. Para cada tratamento, dez plantas foram cultivadas e em média, cinco folhas expandidas foram coletadas e fixadas em FAA 50 (JOHANSEN, 1940) por 48 horas e posteriormente conservadas em etanol a $70 \%$, para as análises anatômicas.

A confecção de lâminas para o estudo anatômico foi realizada no laboratório de anatomia vegetal do departamento de Biologia da Universidade Federal de Lavras. Foram confeccionadas lâminas da epiderme foliar em face frontal (superior e inferior), na qual utilizou-se a metodologia da impressão, a partir da aplicação de uma fina camada de base incolor que, após a secagem, foi cuidadosamente retirada com o auxílio de uma fita adesiva e, posteriormente, fixada às lâminas.

Também foram confeccionadas lâminas semi-permanentes a partir de cortes transversais realizados na região mediana do limbo foliar. O material foi seccionado em micrótomo de mesa com lâmina de aço inox. Tais cortes foram clarificados com hipoclorito de sódio a $50 \%$ por 10 minutos, lavados duas vezes em água destilada por 10 minutos, corados com safrablau (BUKASCH, 1972; BURGER; RICHTER, 1991) por 3 minutos e lavados em água destilada até eliminar todo o excesso de corante. Em seguida, foram montados entre lâmina e lamínula usando, como meio de montagem, gelatina glicerinada. (KAISER, 1880).

Os cortes foram fotografados em microscópio óptico acoplado à câmara digital. Foram confeccionadas escalas nas condições ópticas adequadas.

\section{RESULTADOS E DISCUSSÃO}

As folhas de Mentha $x$ villosa Huds apresentam epiderme unisseriada com células epidérmicas comuns que em vista frontal têm formato alongado de paredes sinuosas (FIG. 16). A epiderme da face adaxial apresenta menor sinuosidade do que a epiderme da face abaxial. A epiderme da face adaxial das folhas de malha preta são menos sinuosas que as demais (FIG. 3, 4). Não houve diferença na espessura das epidermes entre os tratamentos observados, porém, na folha cultivada sob malha preta, a epiderme da face adaxial é mais espessa que a epiderme da face abaxial (FIG. 9). 
Figuras 1-6: Impressões da epiderme foliar de Mentha $x$ villosa Huds. 1, 2: Folhas cultivadas sob pleno sol. 3, 4: Folhas cultivadas sob malha preta. 5, 6: Folhas cultivadas sob malha vermelha. 1, 3, 5: Face adaxial. 2, 4, 6: Face abaxial. Barras $=50 \mu \mathrm{m}$.

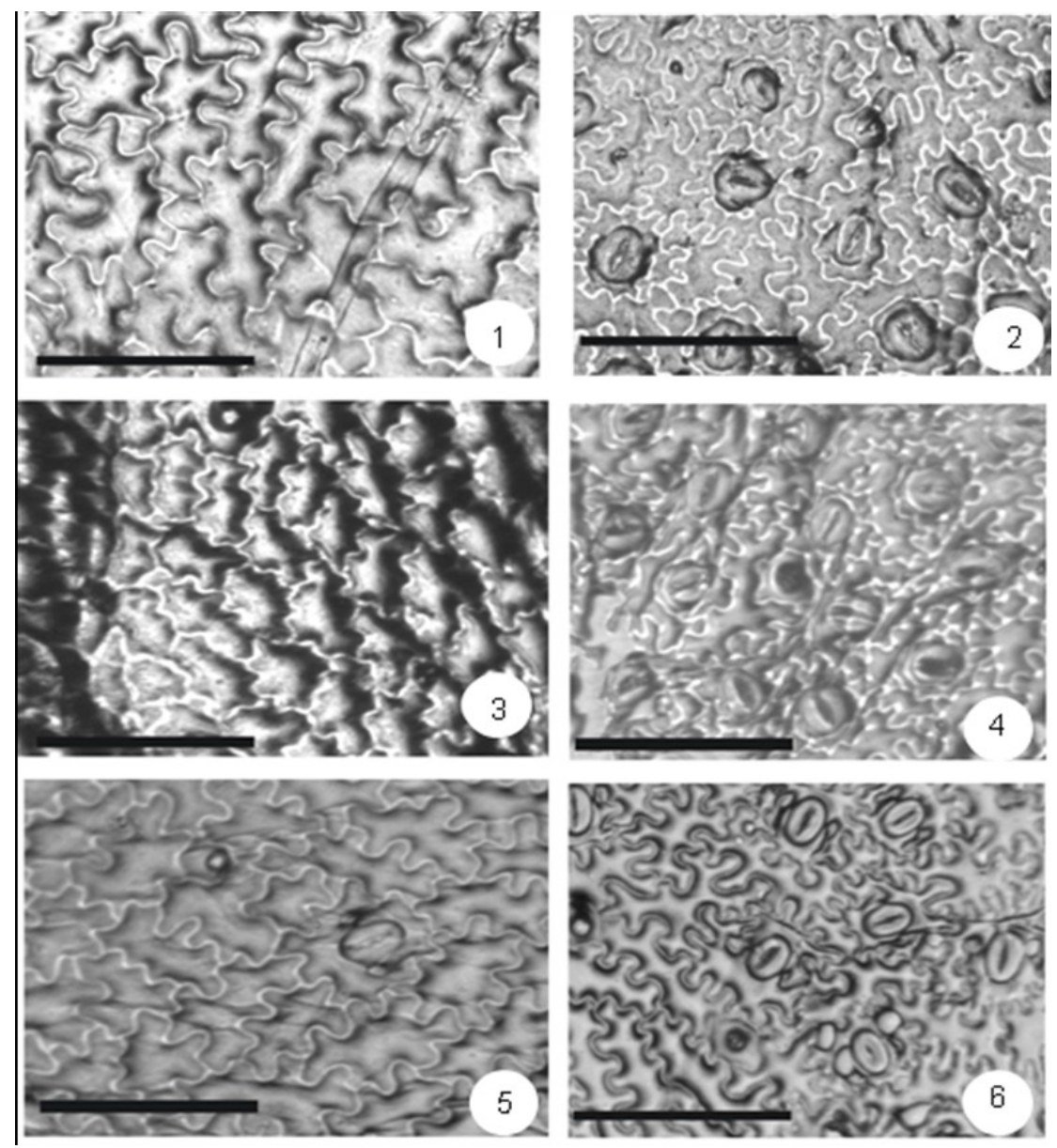

A folha da espécie estudada é anfi-hipoestomática (FIG. 2, 4, 5-6) e o aparelho estomático é do tipo anomocítico. Observou-se que as folhas de hortelã são pilosas, exceto as folhas cultivadas sob malha vermelha. Os tricomas tectores são unisseriados e multicelulares. Os glandulares são bicelulares, com um pedúnculo e uma cabeça secretora. São encontrados tricomas em ambas as faces da epiderme foliar.

A folha de $M$. villosa é classificada como dorsiventral, apresenta parênquima clorofiliano paliçádico na face adaxial e parênquima clorofiliano lacunoso na face abaxial (FIG. 7, 9, 11). Observa-se que na folha de $M$. villosa cultivada sob malha preta existem duas camadas de parênquima clorofiliano paliçádico (fig. 9) diferente das demais que possuem apenas uma camada (FIG. 7, 11). O parênquima clorofiliano lacunoso apresentou variação de três a quatro camadas de células (FIG. 7, 9, 11). O limbo foliar das plantas crescidas a pleno sol possui maior espessura quando comparadas com aquelas crescidas sob as malhas coloridas 
(FIG. 7).

Figuras 7-12: Cortes transversais do limbo foliar e nervura central de Mentha $x$ villosa Huds. 7, 8: Folha cultivada sob pleno sol. 9, 10: Folha cultivada sob malha preta. 11, 12: Folha cultivada sob malha vermelha. Barras $=7,8,10,12: 10 \mu \mathrm{m} ; 9,11: 50 \mu \mathrm{m}$.

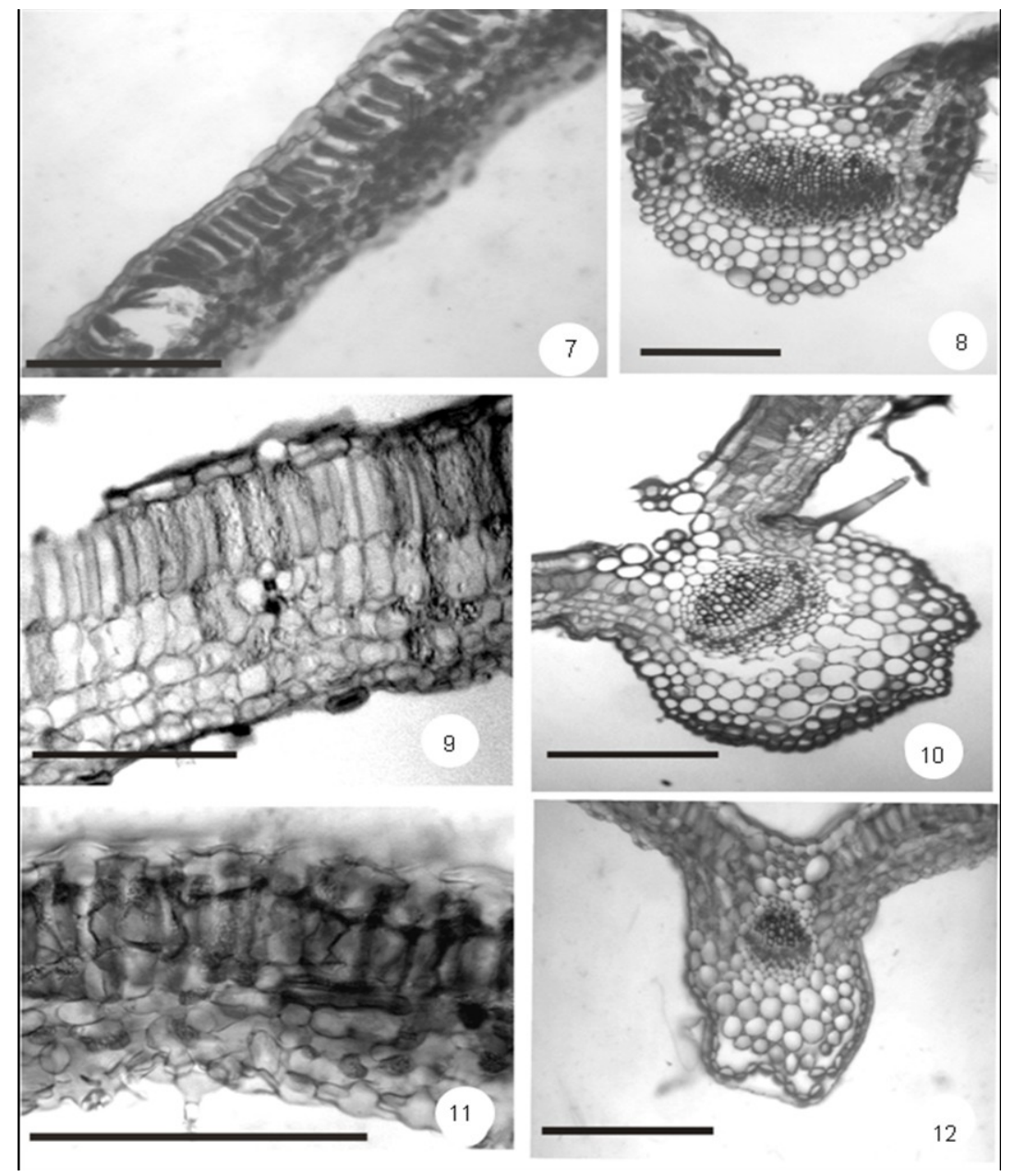

Na região da nervura central, a epiderme é unisseriada, o córtex apresenta células parenquimáticas, com endoderme visível e o sistema vascular apresenta um feixe colateral aberto delimitado pelo periciclo (FIG. 8, 10, 12). Quanto ao feixe vascular, este é mais vigoroso na folha cultivada em pleno sol (FIG. 8) e menor em folhas cultivadas sob malha vermelha (FIG. 12), já o feixe da folha cultivada sob malha preta tem tamanho intermediário (FIG. 10).

\section{CONCLUSÃO}

As mudanças nos espectros de luz proporcionaram algumas alterações na anatomia 
foliar de Mentha x villosa. Destacam-se: variação na sinuosidade das células epidérmicas comuns; folhas glabras de plantas cultivadas sob malha vermelha, mesofilo de folhas cultivadas em malha preta com duas camadas de parênquima paliçádico e sistema dérmico de tamanhos variados entre os diferentes tratamentos.

\section{REFERÊNCIAS}

BERG, M. E. V. Plantas medicinais na Amazônia: contribuição ao seu conhecimento sistemático. 2 ed. rev. e aum. Belém: Museu Paraense Emílio Goeldi, 1993.

BUKASH, F. Bemerkungen zur Doppelfarbung Astrablau-safranin. Mikroskomos, v. 61, p. 255, 1972.

BURGER, L. M.; RICHTER, H. G. Anatomia da madeira. São Paulo: Nobel, 1991.

HANDA, Y. T. et al. The effects of growth irradiance on leaf anatomy and photosynthesis in Acer species differing in light demand. Plant Cell and Enviroment, v. 25, p. 1021-1030, 2002.

JOHANSEN, D. A. Plant microtechnique. New York: McGraw, 1940.

KAISER, E. Verfahren zur Herstellung einer tadellosen Glycerin-Gelatine. Bot Zentralb, p. 25-26, 1880.

SHCLUTER, U. et al. Photosyntetic performance of an Arabidopisis mutant with elevated stomatal density under different light regimes. Journal of Experimental Botany, v. 54, p. 867-874, 2003. 